\title{
LOSS AVERSION IN FINANCIAL MARKETS
}

\section{Liyan Yang}

University of Toronto, Canada

liyan.yang@rotman.utoronto.ca

\begin{abstract}
Experimental evidence suggests that people are more sensitive to losses than gains by a factor of about two. Researchers have drawn implications from loss aversion to understand various aspects of individual decisions and asset prices in financial markets. At the current stage, some ancillary assumptions have been made in deriving these implications. Loss aversion affects financial markets through affecting the risk attitudes of market participants. Taken as a whole, loss aversion is a useful ingredient in helping us understand financial markets.
\end{abstract}

Keywords: Loss aversion, risk attitude, anomalies.

JEL Classification Numbers: G11, G12, D50.

"A central conclusion of the study of risky choice has been that such choices are best explained by assuming that the significant carriers of utility are not states of wealth or welfare, but changes relative to a neutral reference point. Another central result is that changes that make things worse (losses) loom larger than improvements or gains." (Kahneman et al., 1991, p.199)

\section{INTRODUCTION}

T $\mathrm{n}$ financial economics, most theories assume that investors evaluate risks 1 according to the expected-utility framework. ${ }^{1}$ However, researchers find

1 The expected-utility framework was developed by Von Neumann \& Morgenstern (1947) and Savage (1954). Under this framework, an agent derives utility from final wealth levels $w$ at different states according to a concave utility function $u(w)$. For a random wealth $W$, its value according to the expected utility is $E[u(W)]$, where $E[\cdot]$ is the expectation operator under the distribution of $W$.

Copyright (c) Liyan Yang / 4(1), 2019, 119-137. 
that the behavior of individuals and aggregate outcomes in financial markets are sometimes inconsistent with predictions derived from expected-utility maximizers. These observations have motivated the study of various alternative decision theories. One particularly interesting alternative theory is prospect theory, which was proposed in 1979 based on extensive experimental evidence by two psychologists, Amos Tversky and Daniel Kahneman. It is widely believed that this theory offers a sensible way of understanding how people think about risk.

One of the most salient features of prospect theory is loss aversion, ${ }^{2}$ which was introduced to capture the experimental evidence that people tend to reject lotteries such as a 50:50 bet to win $\$ 110$ or lose $\$ 100$. Kahneman \& Tversky (1979) posited that people get both pleasure and pain directly from gains and losses and that they are more sensitive to losses than gains. Formally, people evaluate gains and losses using the following value function:

$$
v(x)=\left\{\begin{array}{cl}
x, & \text { if } x \geq 0, \\
\lambda x, & \text { if } x<0,
\end{array}\right.
$$

where $x>0$ denotes gains and $x<0$ denotes losses. Parameter $\lambda>1$ controls the degree of loss aversion; its empirical value is close to 2 , and we will use this value in this article. When facing a lottery, people first apply this value function to each possible gain and loss, then multiply the respective probability and sum up to arrive at a final value to evaluate how attractive the lottery is. That is, for any lottery $X$, its value according to loss-aversion utility is $E[v(X)]$. For example, for the $50: 50$ bet to win $\$ 110$ or lose $\$ 100$, the value is:

value of taking the bet $=110 * 0.5-2 * 100 * 0.5=-45$,

and thus a loss-averse person would turn down this bet. ${ }^{3}$

Over the past few decades, researchers have made significant progress in applying loss aversion to understanding both individual behaviors-such as trading assets in financial markets and making real investments within a

2 Many other theories, such as disappointment aversion or regret theory, also share similar features to loss aversion.

3 Alternatively, consider an expected-utility maximizer. Suppose that she has an initial wealth of $\$ 75,000$ and has a smooth, concave expected-utility function $u(w)=\ln (w)$. If she turns down the bet, the value is $\ln (75,000)=11.2252$. If she takes the bet, the value is $\ln (75,000$ $+110) * 0.5+\ln (75,000-100) * 0.5=11.2253$. As a result, this expected-utility maximizer would take the bet. 
company - as well as aggregate market outcomes such as asset prices. For financial investors, loss aversion helps to explain their reluctance to allocate any money to the stock market (the "nonparticipation puzzle"), their refusal to hold a well-diversified portfolio if they decide to participate in the stock market at all (the "under-diversification puzzle"), and their tendency to sell better performing stocks than poorer performing ones (the "disposition effect"). For corporate company managers, loss aversion helps to explain their reluctance to shut down projects that are doing poorly, as well as other real decisions such as mergers and acquisitions and dividends payouts. For asset prices, loss aversion helps to explain the high average return on the stock market (the "equity premium puzzle"), the high volatility of stock returns (the "excess volatility puzzle"), the volatility clustering feature of stock returns (the "GARCH effect"), as well as the fact that stock returns can be forecast by various factors in both a time series and cross section.

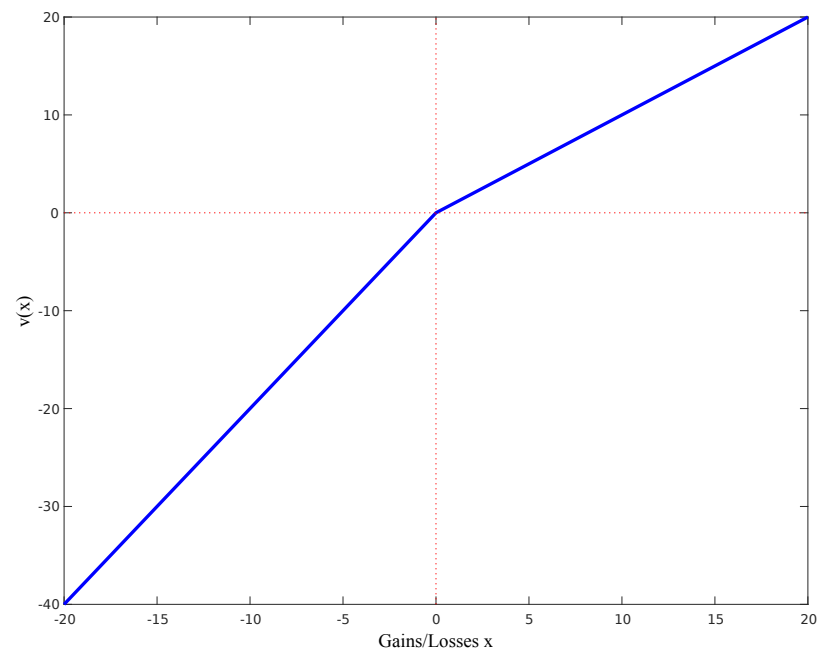

Figure 1: The value function of loss aversion.

Essentially, loss aversion affects the financial market through influencing people's attitude toward risks. To clarify this point, I use Figure 1 to plot the value function $v(x)$ for $\lambda=2$. Loss aversion affects people's risk attitude in three ways. First, the value function in Figure 1 is globally concave, meaning that a loss-averse investor is averse to risks (in economics terms, she behaves 
as if she is risk averse). ${ }^{4}$ This implies that the investor is reluctant to accept a bargain with an uncertain payoff rather than another bargain that has more certainty but also a possibly lower expected payoff. When it comes to the financial market, a loss-averse investor is more inclined to put her money into T-bills with a low but relatively guaranteed return rather than into a stock that has high expected returns, but one that also involves a high chance of losing value. As a result, this global risk aversion induced by loss aversion helps to explain the nonparticipation puzzle, and it can generate a high equity premium in an equilibrium model.

Second, the value function has a "kink" at the origin. This feature is known as "first-order risk aversion" in economic theory. Informally, it means that the investor is locally risk averse, while the traditional expected utility exhibits local risk neutrality. The kink often implies that the investor's optimal decision is sluggish in response to exogenous changes in environments. In terms of financial applications, this feature implies that companies tend to cluster their dividend payouts at a certain level, that potential acquirers tend to cluster their offer prices around a historical high stock price of a targeted firm, and that loss-averse traders choose a zero holding of the risky asset when they trade against non-loss-averse traders.

Third, in a dynamic setting, loss aversion can cause a time-varying risk attitude. Researchers have identified this changing risk aversion generally through two approaches - by borrowing psychological evidence which suggests that sensitivity to loss is dependent on prior gains and losses, or by pinpointing the mismatching of the decision intervals and the evaluation intervals (for example, an investor trades stocks every month over the year, but she only derives loss-aversion utility from the cumulative gains and losses at the year end). A time-varying risk attitude can generate excess volatility and predictability of stock returns through affecting how much compensation a loss-averse investor would require for holding a risky asset.

In the rest of this article, I first present the challenges that researchers face in applying loss aversion in financial markets, then discuss the implications of

4 Informally, "risk aversion" refers to a general preference for safety over uncertainty in potential gains or losses. Loss aversion emphasizes a strong distaste for losing money. In economics, risk aversion is captured by the curvature of the expected utility value function $u(w)$, where $w$ is the agent's overall wealth level. The $u$ function can be related to the value function $v$ of loss aversion. For instance, if the reference point is given by some initial wealth level $w_{0}$ so that the gain or loss $x$ is simply $w-w_{0}$, then one can link $v$ and $u$ as follows: $v(x)=v\left(w-w_{0}\right) \equiv u(w)$. 
loss aversion for individual decisions and asset prices, and finally make some concluding remarks. I want to emphasize that this article is not intended to conduct a complete survey on loss aversion ${ }^{5}$ but instead to illustrate how loss aversion can be applied to help us understand the financial market. I hope that the material in this article can inspire more fruitful research in the area of loss aversion in financial markets and guide market design in scenarios in which loss aversion is present.

\section{THE DIFFICULTY OF APPLYING LOSS AVERSION IN FINANCE}

When researchers apply loss aversion to determine implications for financial markets, they need to make many auxiliary assumptions as it is often unclear how to exactly define gains or losses. There are four related issues here. The first issue is determining whether people engage in "mental accounting" or "narrow framing" when they evaluate their financial investments in multiple assets. For example, suppose that you own a portfolio of two stocks, IBM and Apple. Over the course of the year, your IBM holdings go up in value by $\$ 1,000$ while your Apple holdings go down by $\$ 1,000$. You can frame your investment performance in two ways: by engaging in broad framing, you can look at your overall portfolio performance and thus register $\$ 0$ gain/loss for this broad account; alternatively, you can engage in narrow framing and look at the performance of each stock separately and, in this scenario, feel good about your investment in IBM but feel really bad about your investment in Apple.

The second issue concerns reference points. Again, think about the above example. Say that the framing issue is settled: you accept narrow framing and look at each stock in isolation. But it is still unclear how exactly to measure gains and losses: Does a "gain" mean that the value of the investment exceeds its purchase price, or exceeds its purchase price adjusted by some rate, or exceeds some other targets such as historical high prices or expected future prices? Say the reference point is the purchase price adjusted by the average return on T-bills (perhaps because if the money was put into T-bills, the investment value would have increased on this rate). By a similar reason, an adjustment can be made based on any rate on similar alternatives or the

5 For excellent surveys on prospect theory, or more broadly, behavioral finance, see, for example, Barberis (2013), Barberis (2018), Barberis \& Thaler (2003), Kahneman (2003), and Hirshleifer (2015). 
expected return on the stock under consideration. This reference point issue can become more complicated in a dynamic setting because it often involves the updates of reference points. For instance, suppose that you have bought in Apple at a price of $\$ 500$ per share and the stock has been below that value for quite a while. Would you still keep $\$ 500$ as a reference point or would you adjust it downward since the price has continued to decline for a while?

The third issue is about how frequently investors evaluate their gains or losses. Should gains/losses be checked annually or monthly? Or is there no fixed frequency and an evaluation should be conducted once a trade is completed? Relatedly, trading frequency can be quite different from evaluation frequency, and so temporal framing exists here as well. Consider the following example. Suppose that you purchased a stock at $\$ 1,000$ at the beginning of the year. In June, its value goes down to $\$ 500$, but in December, its value goes up to $\$ 1,500$. Would you count this investment as a total gain of $\$ 500$ (you will if you derive utility from annual gains and losses), or count it as a loss of $\$ 500$ and a gain of $\$ 1,000$ (you will if you think about gains and losses on a semi-annual frequency)? This issue is similar to the first narrow-framing issue, but in that scenario the issue is about evaluating across different assets while here it is about evaluating over different time periods for a given stock (in this sense, this issue can be thought of as an issue of temporal narrow framing).

Finally, the last issue is about whether trading profits have to be realized in order to be counted as a gain or loss. Would a paper loss generate a negative utility? Some people may feel bad even if they only watch their financial wealth fluctuate while for others an unrealized loss is not that painful as long as it is just on paper ("it's only a paper loss-it'll come back").

In all finance applications of loss aversion, researchers have to make assumptions about the above four issues. Most researchers have adopted the assumption of narrow framing or mental accounting and have used purchase prices or a risk-free rate as reference points. For evaluation frequency, some researchers argue that annual frequency seems to be most natural, perhaps because the performance of most asset classes is often reported in annual terms. Most of the studies have also assumed that people care about paper gains or losses, which is particularly true for asset-pricing models, because in these models, there is typically no trading and thus no gains or losses are realized. ${ }^{6}$

6 Barberis \& Xiong (2012) and Ingersoll \& Jin (2013) have studied the implications of "realization utility" in which people derive utility only from realized gains or losses. 


\section{IMPLICATIONS FOR INDIVIDUAL BEHAVIORS}

\subsection{Nonparticipation in the Stock Market}

For much of the twentieth century, most households did not invest any money in stocks, even though the stock market has offered a high mean rate of return. For instance, in 1984, only $28 \%$ of U.S. households held any stock, and only $12 \%$ held more than $\$ 10,000$ in stock. Today, the fraction of households that own stock is close to $50 \%$. This behavior is puzzling because standard finance theory predicts that people should invest at least some money in the stock market, which offers an actuarially favorable gamble. Researchers have argued that loss aversion is useful for explaining the nonparticipation puzzle: loss aversion means that investors are more sensitive to losses than to gains and since stock returns are volatile, holding stocks would make investors often face losses and thus they are reluctant to invest in the stock market.

An example is helpful. In the U.S., historically, the annual stock market return has a mean of $6 \%$ and a volatility of $20 \%$. To match this data, let us suppose that if a current investor puts $\$ 10,000$ in a stock, the next year she may gain $\$ 2,600$ or lose $\$ 1,400$ with equal probability. To compute the value that a loss-averse investor would place on this investment, let us assume that she uses the purchase price as the reference point and computes loss-aversion utility based on the trading profit over the year. So this investor would simply multiply each outcome by its probability and keep in mind that there is double sensitivity to losses (i.e., $\lambda=2$ ), yielding:

value of participating in stock markets $=2,600 * 0.5-2 * 1,400 * 0.5=-100$,

which is smaller than 0 , or the value that she would place if there was no investment in the stock market. This explains the nonparticipation puzzle.

Barberis et al. (2006) caution that the above argument has implicitly incorporated the important assumption of "narrow framing;" that is, when people think about whether to invest in the stock market, they may be thinking about it in isolation rather than in combination with other risks that they are already facing such as fluctuations in labor income and house prices. If we extend this narrow-framing assumption to an asset class level or to an individual stock level, then by the same logic, loss aversion is also useful for understanding other related puzzles: the home bias puzzle, the refusal of many households to invest in international equities; and the under-diversification puzzle, which 
is the tendency of some stockholders to hold only a small number of stocks, rather than many stocks for the benefits of diversification.

\subsection{The Disposition Effect}

Another often-studied financial phenomenon is the "disposition effect," which concerns how people trade assets over time. The disposition effect posits that both individual investors and mutual fund managers have a greater tendency to sell assets that have risen in value since the purchase than those that have fallen. This effect has been repeatedly observed both in experiments and in real markets in which people trade stocks, houses, or stock options. It is puzzling because most obvious rational explanations, such as portfolio rebalancing or information story, cannot entirely account for the effect. For example, stock markets exhibit "momentum"-i.e., stocks that have done well over the past six months continue to outperform other stocks, on average, while stocks that have done poorly over the past six months continue to lag. As such, the rational thing to do is to retain stocks that have recently risen in value and sell those that have recently fallen in value, which is the opposite of the disposition effect.

The literature has pointed to loss aversion as a potential ingredient underlying the disposition effect. ${ }^{7}$ For example, in explaining disposition behavior in the Boston condominium market, Genesove \& Mayer (2001, p.1235) wrote: "When house prices fall after a boom, as in Boston, many units have a market value below what the current owner paid for them. Owners who are averse to losses will have an incentive to attenuate that loss by deciding upon a reservation price that exceeds the level they would set in the absence of a loss, and so set a higher asking price, spend a longer time on the market, and receive a higher transaction price upon a sale." Recent theoretical research, however, suggests that the link between loss aversion and the disposition effect is more nuanced.

Li \& Yang (2013a) find that loss aversion can either drive a disposition effect or a reversed disposition effect (that people are more inclined to sell losers than winners), depending on the skewness of the stock return process. ${ }^{8}$

7 Another component of prospect theory is diminishing sensitivity, that is, people are risk averse over gains and risk seeking over losses, which has also been commonly cited to explain the disposition effect.

8 Skewness is computed as the third standardized moment of stock returns. It is a measure of the asymmetry of the return distribution about the mean. When the return distribution is symmetric, its skewness is zero. Negative skewness suggests that the return distribution is 
In their setting, a loss-averse investor buys shares of a stock at the beginning of the year. Over the course of the year, she trades the stock and at the end of the year receives loss-aversion utility based on her trading profit. In this setting, the underlying link between loss aversion and the selling behavior is essentially a time-varying risk attitude story. Loss aversion means that the value function has a kink at the origin and the investor is afraid of holding stocks if she is close to the kink. In Fig. 1, the value function is locally concave at the origin (the investor is locally risk averse when her current gain or loss is close to zero), while it is locally linear at a deep gain or loss (the investor is locally risk neutral when she has already accumulated many gains or losses). Whether loss aversion drives a disposition effect depends on whether good news or bad news moves the investor closer to the kink. Now suppose that the stock return process is negatively skewed. The odds of bad news are then very small but once the news occurs, its size is very large, dragging the investor down to a deep loss at a position very far away from the kink. In contrast, good news occurs more frequently but of a small order, leaving the investor close to the kink when facing gains. As a result, with bad news, the investor will be less afraid of risk and more likely to hold the stock, thus generating the disposition effect. In the case of a positively skewed stock return process, the opposite happens, leading to a reversed disposition effect. ${ }^{9}$ Again, let us use an example. Suppose that you have invested $\$ 10,000$ in a stock in January and you will evaluate this investment based on the cumulative gains or losses at the end of December in a way as described by loss aversion. Let us also suppose that over any six-month period, the stock return can be either $11 \%$ with a probability of 0.75 , or $-23 \%$ with a probability of 0.25 . This return distribution is left-tailed with a skewness of -1.15 . Now let us fast forward six months to June and suppose that the stock investment has gone up to $\$ 11,100$ $(=10,000 *(1+11 \%))$. What will you do now? If you sell the stock, you can

left-tailed, that is, for most of the time, stock returns are positive and relatively small, but with small probabilities, there can be quite large price drops. Positive skewness suggests the opposite.

9 Li \& Yang (2013a) specify that the reference point is the stock's purchase price or equivalently the investor's initial wealth. Meng \& Weng (2018) show that if the reference point is based on expected wealth rather than initial wealth, prospect theory can generate a disposition effect even for non-skewed stock return processes. Pagel (2016) suggests that expectation-based reference points are also relevant for understanding asset price behaviors. 
lock in a gain of $\$ 1,100$ and its value under loss-aversion utility is

$$
\text { value of selling }=1,100 \text {. }
$$

In contrast, if you decide to keep the stock and if you're lucky, the stock will continue to go up and at the end of December your investment will become $\$ 12,321\left(=11,100^{*}(1+11 \%)\right)$. This returns a total gain of $\$ 2,321$, with a probability of 0.75 . If you are unlucky and the stock drops in December, your investment will drop to $\$ 8,547(=11,100 *(1-23 \%))$ with a probability of 0.25 , generating a total loss of $\$ 1,453$. As a result, the value is:

value of holding $=2,321 * 0.75-2 * 1,453 * 0.25=1014.30$,

which is smaller than the value 1,100 of selling. So you may want to sell the stock in June after it has gone up.

Now suppose that in June the stock has gone down to $\$ 7,700(=10,000 *(1-$ $23 \%)$ ). If you sell the stock, you will incur a loss of $\$ 2,300$, which implies

$$
\text { value of selling }=-2 * 2,300=-4,600 \text {. }
$$

By contrast, if you hold the stock until December, then the stock can go up to $\$ 8,547(=7,700 *(1+11 \%))$ with a probability of 0.75 , leaving a relatively small overall loss of $\$ 1,453$, or it can continue to drop to $\$ 5,929(=7,700 *(1-23 \%))$ with a probability of 0.25 , leading to a large total loss of $\$ 4,071$. Thus, the loss-aversion utility of keeping the stock is

value of holding $=-2 * 0.75 * 1,453-2 * 0.25 * 4,071=-4,215$,

which is larger than the value $-4,600$ if you sold the stock. Thus, you may want to keep the stock after the stock has declined in June. So, facing bad news in June, you hold on to the stock, while facing good news in June, you close the position, which is the disposition effect. Note that underlying this effect is that bad news moves you further away from the kink with a relatively large loss of $\$ 2,300$ than good news with a relatively small gain of $\$ 1,100$.

\subsection{Corporate Decisions}

Researchers find that loss aversion is also useful in understanding corporate decisions that affect real resource allocations. For example, similar to the 
disposition effect in the financial market, managers are reluctant to divest or shut down projects that are doing poorly. So, as loss aversion explains the disposition effect, it can also justify a reluctance to terminate bad real investments.

Baker \& Wurgler (2013) argue that loss aversion is a useful ingredient for understanding dividend policies. They construct a dynamic model in which a benevolent firm manager decides how many dividends to pay out to her investors. Investors are loss averse in the sense that the negative effect of a $\$ 1$ drop in dividends below the current reference point is greater than the positive effect of a $\$ 1$ increase in dividends. In their model, the reference point in the current period is the dividend level set in the previous period. So although increasing dividends today have the benefit of avoiding falling short of today's reference, they also have the cost of raising tomorrow's reference point and the likelihood of generating future losses. The optimal dividend policy is determined by this tradeoff. Because of the loss-aversion kink feature, Baker $\&$ Wurgler (2013) find that the optimal dividend payout often clusters at a certain level and adjusts only when earnings are sufficiently large. This prediction is largely consistent with existing empirical literature.

Baker et al. (2012) suggest that loss aversion also helps to understand various aspects of merger and acquisition activity. They argue that historical peak prices, such as the 13-week high or the 52-week high, can serve as the natural reference point for an offer price because these peak prices are routinely reported and discussed in the financial press and thus salient to all related parties. They find that in their sample, offer prices cluster around these peak prices. In their interpretation, one important element is that loss aversion affects both the psychology of the target's management and shareholders and that of the bidder's management. For instance, from the target's perspective, the reluctance to realize losses relative to a reference point (i.e., the disposition effect in the trading behavior reviewed in the previous section) implies that targets are more likely to approve mergers in which the offer price approaches or exceeds a recent peak price (as a reference price). Finally, Baker et al. (2012) also find that their anchoring story can explain bidder announcement effects, deal successes, and merger waves. 


\section{IMPLICATIONS FOR ASSET PRICES}

\subsection{The Equity Premium Puzzle}

The equity premium puzzle has to do with the fact that the average return on the aggregate stock market has historically been much higher than the average return on Treasury bills over the past century. The equity premium can range from $4 \%$ to $8 \%$ on an annual basis, depending on the source datasets. Of course, since the stock market is riskier than T-bills, the average stock return should be higher than the average return on T-bills. The problem is that traditional models can only generate an annual equity premium smaller than $0.5 \%$. Thus, the equity premium puzzle is a quantity puzzle: Why has the historical equity premium been so consistently high?

One of the most robust predictions of loss aversion is a sizeable equity premium in an equilibrium model. The intuition is simple. Loss aversion means that investors are more sensitive to losses than to gains. Since stocks often perform poorly and thus investors often face losses, a large premium is required to convince them to hold stocks. Since the equity premium puzzle is about magnitude, let us use the following example-in the spirit of Benartzi \& Thaler (1995) calibration exercise - to illustrate how loss aversion can generate an equity premium as high as its historical value.

For simplicity, let us suppose that the T-bill rate is zero so that the equity premium is the average stock return. Suppose that the stock market can go up or down so that the annual stock return can take two values, $r_{u}>0$ and $r_{d}<0$, with equal probability. Under this distribution, the average and volatility of stock returns are

$$
\text { ret.avg. }=0.5 *\left(r_{u}+r_{d}\right) \text { and ret.vol. }=0.5 *\left(r_{u}-r_{d}\right) .
$$

We fix the return volatility at its historical value $20 \%$ (i.e., $0.5 *\left(r_{u}-r_{d}\right)=$ $20 \%$ ), and check whether loss aversion can deliver a high average return. Suppose that investors are loss averse in financial markets; they like gains and dislike losses and they are doubly sensitive to losses than to gains. Since these investors hold both T-bills and stocks, they must be indifferent to holding these two assets. Holding the T-bill delivers no gains or losses and thus the value is zero, which in turn means that the value of holding the stock has to be zero as well. Since investing $\$ 1$ in the stock will deliver a gain of $r_{u}>0$, or a loss of $r_{d}<0$, with equal probability, its value is

value of holding the stock $=0.5 * r_{u}+2 * 0.5 r_{d}=0$. 
Combining the above equation with $00.5 *\left(r_{u}-r_{d}\right)=20 \%$, we can compute $r_{u}=27 \%$ and $r_{d}=-13 \%$, which implies an annual equity premium of $0.5 *$ $\left(r_{u}+r_{d}\right)=7 \%$ !

\subsection{Return Volatility}

Stock return volatility has two salient features. First, its level is surprisingly high, relative to the volatility of dividends (which are a proxy for fundamentals). For instance, the U.S. stock market has a return volatility of $20 \%$ on an annual basis while the volatility of dividend growth is around $6 \%$ for the post-war period. This fact is termed the "excess volatility puzzle" in the literature. Second, return volatility is highly persistent, or in statistical terms, returnvolatility autocorrelation is very high, which is known as a "GARCH effect." Researchers have found that loss aversion can shed light on both features of return volatility.

The reason that loss aversion helps to explain the excess volatility puzzle is that loss aversion can generate a time-varying risk aversion in a way such that people are more risk averse after bad news than after good news. The intuition is straightforward—after bad (good) news, the stock market goes down (up); people thus become more (less) risk averse and more (less) anxious holding the stock, pushing the stock price down (up) even further, which amplifies the volatility of the stock market to a greater extent than can be justified by the volatility of fundamentals alone.

Again, let us use an example to illustrate this point. Suppose that a stock was worth $\$ 33.67$ per share last year and that it paid a dividend of $\$ 1.00$. Also suppose that each year it is equally likely that the stock's dividend can increase either by $7 \%$ or decrease by $5 \%$ so that the average dividend growth rate is $\mu_{D}=0.5 *(7 \%-5 \%)=1 \%$ and the volatility of dividend growth rate is $\sigma_{D}=0.5 *(7 \%+5 \%)=6 \%$. In a traditional model with constant risk aversion, the discount rate would be constant, so let us assume that it is $4 \%$. Let us also assume that the stock is priced according to a standard textbook Gordon formula as follows:

price of the stock $=\frac{\left(1+\text { average dividend growth rate } \mu_{D}\right) \times \text { current dividend }}{\text { discount rate }- \text { average dividend growth rate } \mu_{D}}$.

Now, suppose that the dividend news is good this year so that the stock's underlying firm issues a dividend of \$1.07. According to the Gordon formula, 
the stock price rises to $\frac{(1+1 \%) \$ 1.07}{4 \%-1 \%}=\$ 36.02$, where the cash flow is discounted at the rate of $4 \%$. So, given the good dividend news this year, the stock return is

$$
r_{u}=\frac{\$ 36.02+\$ 1.07}{\$ 33.67}-1 \approx 10 \% .
$$

Similarly, suppose that the dividend news is bad this year and thus the dividend drops to $\$ 0.95$. Again, the Gordon formula implies that the stock price drops to $\frac{(1+1 \%) \$ 0.95}{4 \%-1 \%}=\$ 31.98$, and therefore the stock return is

$$
r_{d}=\frac{\$ 31.98+\$ 0.95}{\$ 33.67}-1 \approx-2 \%
$$

As a result, the return volatility is $0.5 *\left(r_{u}-r_{d}\right)=6 \%$, which is the same as the dividend volatility.

What will happen if the risk attitude (and hence the equilibrium discount rate) becomes time varying? Let us suppose that with good news, the marginal investor becomes less risk averse so that the discount rate drops to $3.5 \%$ while with bad news, the investor becomes more risk averse and the discount rate rises to $4.5 \%$. If this year the firm is doing well and issues a dividend of $\$ 1.07$, then the stock price jumps to $\frac{(1+1 \%) \$ 1.07}{3.5 \%-1 \%}=\$ 43.23$, where the cash flow is discounted at the lower rate of $3.5 \%$. So, the stock return with good news is

$$
r_{u}=\frac{\$ 43.23+\$ 1.07}{\$ 33.67}-1 \approx 32 \% .
$$

Similarly, suppose that the dividend news is bad this year and the dividend drops to $\$ 0.95$. By the higher discount rate of $4.5 \%$, the stock price then drops to $\frac{(1+1 \%) \$ 0.95}{4.5 \%-1 \%}=\$ 27.41$ and therefore the stock return is

$$
r_{d}=\frac{\$ 27.41+\$ 0.95}{\$ 33.67}-1 \approx-16 \% \text {. }
$$

Now the return volatility becomes $0.5 *\left(r_{u}-r_{d}\right)=24 \%$, which is much higher than the dividend volatility $6 \%$.

The literature has used loss aversion to induce a changing risk aversion in two ways. First, Barberis et al. (2001) directly borrow another reasonable psychological assumption - the "house money effect" - and assume that losses are less painful to people if they occur after prior gains and more painful if they follow prior losses. Second, Li \& Yang (2013a) show that this changing risk 
aversion can emerge endogenously because of a reversed disposition effect, which is ultimately driven by a time-varying, risk-aversion mechanism, as explained in Section 3.2. Underlying Li and Yang's theory is the existence of a discrepancy between trading frequency and evaluation frequency: although investors can trade over the course of a year, they evaluate investment performance only at the end of each year; when they retrade over the year, previous return realizations can change their location relative to the kink, which in turn shifts their risk attitude.

McQueen \& Vorkink (2004) show that dynamic loss aversion also helps to explain volatility clustering found in low-frequency stock returns. They add a new feature to the framework developed by Barberis et al. (2001), namely, that after a large shock or several shocks of the same sign, investors not only become more or less risk averse, but they also become perturbed and thus more attentive to subsequent future news. This implies that any prominent news today will cause stock prices to react more to news tomorrow and hence future return volatility becomes higher, leading to volatility clustering in stock returns.

\subsection{Return Predictability}

Stock returns are forecastable. First, future stock returns can be predicted by past returns. On a six-month-to-one-year horizon, returns exhibit "momentum": stocks that have done well (poorly) over the past six months tend to keep doing well (poorly) over the next six months. In contrast, on a longer horizon, returns exhibit "reversal"; for instance, stocks that have done well (poorly) over the past three years tend to do poorly (well) in the future. Second, stock returns can be predicted by many other economic variables, such as price-dividend ratios, book-to-market ratios, and dividend volatility. For instance, the pricedividend ratio is able to explain more than $20 \%$ of the variation of NYSE stock returns; the "value premium" says that stocks with higher book-to-market ratios (i.e., value stocks) have higher average returns. Loss aversion is useful for understanding both types of return predictability through two approaches.

The first approach works through the time-varying, risk-aversion feature implied by dynamic loss aversion as we discussed earlier in Barberis et al. (2001) or in Li \& Yang (2013a). For instance, in Barberis et al. (2001), investors become more risk averse after bad news, thus stock returns exhibit reversal—bad news pushes down prevailing prices and raises investors' risk 
aversion, leading to higher expected future returns as compensation for this raised risk aversion. The same mechanism also generates a value premium in the cross section: a stock with a low market-to-book ratio has often done badly in the past, accumulating prior losses for the investor, who then views it as riskier and requires a higher average return.

The second approach relies on an exogenous time-varying fundamental process to generate return predictability. For instance, Li \& Yang (2013b) first document that dividends feature volatility clustering at both the aggregate level and the individual firm level, and then build this fact into a pricing model with loss-averse investors to show that dividend volatility is a robust predictor of future returns. Specifically, higher dividend volatility corresponds to a more volatile investment environment and hence more fluctuation in the investment values, which implies that potential losses faced by investors are now larger. This makes risky assets less desirable. As a result, investors may require more compensation when facing more volatile dividend processes, which, in turn, results in lower prices and higher equity premia.

\subsection{What If Not All Investors are Loss Averse?}

In previous applications of loss aversion on asset prices, researchers have typically assumed that all investors in the financial markets are loss averse. What happens if some investors are not? Answering this question is important because it can help us to qualify and quantify the pricing implications of loss aversion. Easley \& Yang (2015) and Guo \& He (2017) take on this task and examine the interactions between loss-averse investors and non-loss-averse investors. The key result of these studies is that the kink feature induced by loss aversion discourages loss-averse investors from holding risky assets, which significantly limits the pricing implications of loss aversion. Take the equity premium puzzle as an example. If all investors are loss averse, then the annual equity premium can be as high as $7 \%$, as discussed above. However, if only half of investors exhibit loss aversion while the other half do not, then the equity premium may be only as low as $1 \%$. In addition, even if loss-averse investors initially hold the majority of wealth so that the equity premium is initially very high, after a few years of trading, the equity premium can drop significantly because loss-averse investors are unwilling to participate in the equity market. These observations suggest that when we draw implications of loss aversion, we need to be careful about the heterogeneity of the investor base. For instance, 
retail investors are believed to be more loss averse than institutional investors thus the pricing implications discussed in the previous section may be more pronounced among stocks with lower institutional ownership.

\section{CONCLUDING REMARKS}

Over the past few decades, a sizable literature has emerged to analyze the implications of loss aversion for individual decisions and aggregate market outcomes. The literature is both theoretical and empirical and in this article, I have sought to synthesize some of the main themes and insights. I hope that this discussion will stimulate future research.

Loss aversion means that people perceive more disutility from losses than utility from equal-sized gains. The fundamental difficulty of applying loss aversion in finance is that defining gains and losses is very elusive and often context-specific. Still, researchers have made significant progress in drawing implications from loss aversion and found that it is useful in understanding investors' trading behavior, firm managers' real investment behavior, and the properties of stock returns. Generally speaking, loss aversion affects financial markets through changing market participants' risk attitudes: it makes people both globally and locally risk averse and induces risk attitudes to vary with prior gains and losses.

I make three main points in concluding this article. First, although loss aversion proves very useful in understanding financial markets, many ancillary assumptions are needed in order to build appropriate models. Such assumptions are crucial in deriving meaningful results. For example, it is the combination of narrow framing and loss aversion, not just loss aversion alone, that explains the nonparticipation puzzle and the equity premium puzzle. Thus, it remains important to build theories that shed light on the choice of these ancillary assumptions, in turn, presenting another great opportunity for research on loss aversion.

Second, most of the applications for market outcomes concern asset prices in a symmetric-information setting. It would be exciting to see whether loss aversion also delivers important implications for other aggregate outcomes, such as volumes or information efficiency in settings with asymmetric information. Li \& Yang (2013a) have made an attempt to link loss aversion to price-volume dynamics. Pasquariello (2014) finds that loss aversion induces speculators to trade less or not at all with private information which may 
mitigate speculators' perceived risk of a trading loss. This result may have important implications for market efficiency and serve as a good starting point for future research on loss aversion in asymmetric-information settings.

Finally, some normative issues regarding loss aversion remain to be resolved and resolving these issues has important implications for market design. There are two dramatically different views that deliver contrasting policy implications. On the one hand, one can argue that loss aversion has some bias and can reduce people's welfare and thus with education, one can correct this bias and achieve a better welfare result. On the other hand, loss aversion may be innate, and how people behave reveals what they feel (prefer). Some economists even show that monkeys also exhibit loss aversion, suggesting that loss aversion is indeed a biological reaction, which may be a result of evolution. Further research is needed to advance our understanding of this dimension.

\section{References}

Baker, M., Pan, X., \& Wurgler, J. (2012). The effect of reference point prices on mergers and acquisitions. Journal of Financial Economics, 106, 49-71.

Baker, M., \& Wurgler, J. (2013). Behavioral corporate finance: An updated survey. In G. M. Constantinides, M. Harris, \& R. Stulz (Eds.), Handbook of the Economics of Finance (Vol. 2, pp. 351-417). Amsterdam: Elsevier.

Barberis, N. (2013). Thirty years of prospect theory in economics: A review and assessment. Journal of Economic Perspectives, 27, 173-196.

Barberis, N. (2018). Psychology-based models of asset prices and trading volume. In D. Bernheim, S. DellaVigna, \& D. L. (Eds.) (Eds.), Handbook of Behavioral Economics (Vol. 1, pp. 79-175). Amsterdam: North Holland.

Barberis, N., Huang, M., \& Santos, T. (2001). Prospect theory and asset prices. Quarterly Journal of Economics, 116, 1-53.

Barberis, N., Huang, M., \& Thaler, R. (2006). Individual preferences, monetary gambles, and stock market participation: A case for narrow framing. American Economic Review, 96, 1069-1090.

Barberis, N., \& Thaler, R. (2003). A survey of behavioral finance. In G. M. Constantinides, M. Harris, \& R. E. R. Stulz (Eds.), Handbook of the Economics of Finance (Vol. 1, pp. 1053-1128). Amsterdam: Elsevier.

Barberis, N., \& Xiong, W. (2012). Realization utility. Journal of Financial Economics, 104, 251-271.

Benartzi, S., \& Thaler, R. (1995). Myopic loss aversion and the equity premium puzzle. Quarterly Journal of Economics, 110, 73-92. 
Easley, D., \& Yang, L. (2015). Loss aversion, survival, and asset prices. Journal of Economic Theory, 160, 494-516.

Genesove, D., \& Mayer, C. (2001). Loss aversion and seller behavior: Evidence from the housing market. Quarterly Journal of Economics, 116, 1233-1260.

Guo, J., \& He, X. (2017). Equilibrium asset pricing with Epstein-Zin and loss-averse investors. Journal of Economic Dynamics and Control, 76, 86-108.

Hirshleifer, D. (2015). Behavioral finance. Annual Review of Financial Economics, 7, 133-159.

Ingersoll, J. E., \& Jin, L. (2013). Realization utility with reference-dependent preferences. Review of Financial Studies, 26, 723-767.

Kahneman, D. (2003). Maps of bounded rationality: Psychology for behavioral economics. American Economic Review, 93, 1449-1475.

Kahneman, D., Knetsch, J. L., \& Thaler, R. (1991). Anomalies: The endowment effect, loss aversion, and status quo bias. Journal of Economic Perspectives, 5, 193-206.

Kahneman, D., \& Tversky, A. (1979). Prospect theory: An analysis of decision under risk. Econometrica, 47, 263-291.

Li, Y., \& Yang, L. (2013a). Prospect theory, the disposition effect, and asset prices. Journal of Financial Economics, 107, 715-739.

Li, Y., \& Yang, L. (2013b). Asset-pricing implications of dividend volatility. Management Science, 59, 2036-2055.

McQueen, G., \& Vorkink, K. (2004). Whence garch? A preference-based explanation for conditional volatility. Review of Financial Studies, 17, 915-949.

Meng, J. E., \& Weng, X. (2018). Can prospect theory explain the disposition effect? A new perspective on reference points. Management Science, 64, 3331-3351.

Pagel, M. (2016). Expectations-based reference-dependent preferences and asset pricing. Journal of the European Economic Association, 14, 468-514.

Pasquariello, P. (2014). Prospect theory and market quality. Journal of Economic Theory, 149, 276-310.

Savage, L. (1954). The Foundations of Statistics (2nd ed.). New York City, NY: Wiley.

Von Neumann, J., \& Morgenstern, O. (1947). Theory of Games and Economic Behavior (2nd ed.). Princeton, NJ: Princeton University Press. 